\title{
A HUMANISTIC APPROACH TO ORGANIZATIONS AND TO ORGANIZATIONAL DECISION-MAKING
}

\author{
Josep M. Rosanas
}




\title{
A HUMANISTIC APPROACH TO ORGANIZATIONS AND TO ORGANIZATIONAL DECISION-MAKING
}

\author{
Josep M. Rosanas
}

\begin{abstract}
This paper attempts to take steps towards the formulation of a more human approach to the theory of the firm than the conventional economics-based models. Unbounded rationality, selfinterest and the absence of learning are shown to be crucial assumptions of conventional economic theory. Then, the essential assumptions of an alternative approach are put forward and discussed. Next, I present an alternative view of organizations, which has its foundations in the concepts of mission, distinctive competence, identification and unity. Finally, the implications of such an approach for management decision-making are shown, emphasizing that three criteria have to be considered in any non-trivial decision in an organizational context.
\end{abstract}

Keywords: theory of the firm, bounded rationality, self-interest, distinctive competence, mission, identification.

\section{Acknowledgements}

I am indebted first of all to Juan Antonio Pérez López, who inspired the last part of the paper but passed away many years before it was ever written. I thank Rafael Andreu, Jordi Canals, Josep Riverola, Manuel Velilla, and the participants in the IESE Conference on "Humanizing the Firm and the Management Profession" (June/July 2008) for comments, suggestions and stimulating discussions on the subject.

\footnotetext{
${ }^{1}$ Professor of Accounting and Control Department, Crèdit Andorrà Chair of Markets, Organizations and Humanism, IESE
} 


\section{A HUMANISTIC APPROACH TO ORGANIZATIONS AND TO ORGANIZATIONAL DECISION-MAKING}

\section{Changes in Business Schools}

Research in management has changed a lot in the last half-century. At the same time, business schools and what they teach have also changed, though whether business schools have changed because the research agenda has changed or vice versa is open to question. What sparked the change, namely the Ford Foundation and Carnegie Foundation reports, how these reports changed the spirit of business schools and how this change has led to the current situation has been well documented by Khurana (2007).

One dimension of the change has been the explosion in the number of publications. In 1960, in my own original field of accounting, there was one academic journal (The Accounting Review); now, there are well over fifty, of different degrees of quality, including five or six top journals. Much the same can be said, I believe, of all the other fields of management. The EBSCO database contains over a thousand journals that have to do with management.

The change in quantity has been accompanied by qualitative changes, essentially in three directions: (i) the increasing importance of the basic disciplines (economics, sociology, psychology) in the research conducted in business schools; (ii) the emphasis on empirical methods, particularly those based on statistical techniques, often considered (implicitly perhaps) the only source of scientific validity; and (iii) a much higher degree of specialization in the research being done. If we had taken at random one article from any of the journals that existed in 1960 and had read the title to the average management professor of that time, the professor would probably have known more or less what the article was about. Today, it would be pure chance if an average management professor could guess the content of an article outside his/her (possibly narrow) field of specialization just by its title. Even within a functional area (say, finance) the title might not be enough for some finance faculty to guess the article's content.

To some extent the same has happened in many disciplines, including the hard sciences. In management, however, which has important interdisciplinary elements, the change has perhaps had greater consequences and has raised concerns about the way human beings are considered and treated both in theoretical analysis and in practice. Gary Hamel proposes "reinventing management", making firms "more resilient", "as nimble as they are efficient", and "more uplifting and a lot less dispiriting" (Hamel, 2007). Donaldson (2008) proposes a "Positive 
Management Theory", with a "positive" view of managers in particular and of human beings in general, as opposed to the "anti-management theories" so popular nowadays (Donaldson, 2003). Davis, Schoorman and Donaldson (1997) advance "stewardship theory" in the same spirit of "positive" human beings and a "human" organization. Ghoshal and Moran (1996) argued that "opportunism", one of the bases of transaction cost economics, may be a self-fulfilling prophecy; in his often cited posthumous article, Ghoshal raised important issues as to the basic ("pessimistic") assumptions about human beings on which the economics models are built (Ghoshal, 2005). Ferraro, Pfeffer and Sutton (2005) argue, more generally, that the language and assumptions of economics make theories self-fulfilling.

According to these views, a different approach to the analysis of organizations is needed, one that brings a more humanistic and realistic spirit to the task. The main objective of this paper is to provide some bases for an alternative way of looking at organizations, one that: (i) departs from the current assumptions and has a more "human face"; (ii) has a logically consistent, rational basis that retains the good, rigorous properties of the economic models and can be tied in with the economics framework; and (iii) is at the same time more operational than the usual economic approaches.

\section{The influence of economics}

The basic discipline that has had by far the most influence on business school teaching and research is neoclassical economics (Gintis and Khurana, 2006). As a result, variables that are crucial for decision-making are simply assumed away, while management risks losing its essence, as we will try to show below. On the other hand, economics has the advantage of being a well-structured theory, with a well-developed formal apparatus, a theory that attempts to be comprehensive and where every issue can find its place and context.

Economics has strongly influenced the strategy field, for instance, through industrial economics, which analyzes individual industries to see whether and how in a given context a particular firm may have a competitive advantage. This is no doubt an interesting approach that has shed some light on real world phenomena, but it neglects cooperation in favor of rivalry and mistrust. More importantly, it overlooks each firm's distinctive competence and specific strengths. One of the basic assumptions of economic theory, namely the primacy of self-interest, is surely one of the reasons for that omission.

The influence of economics is by no means confined to strategy, however. Other areas of management, including finance and accounting, are so heavily influenced by economics or econometrics as to be almost enslaved to them. Perhaps unwillingly, even marketing and organizational behavior often fall under the sway of economic concepts and methods of analysis, such as shareholder value, self-interest, or an instrumental, even mechanistic view of human beings.

Three basic assumptions of economic theory are particularly important. Two of them are quite explicit: self-interest and unbounded rationality. The other is only implicit: a static view of individuals which assumes that individuals do not learn, i.e., that they do not change their preferences, abilities or attitudes. When applied to the analysis of organizations, these assumptions result in a model of the firm that is not too different from the idealized market of economic theory: relationships between people are impersonal, guided only by self-interest and based on perfect knowledge of action alternatives, their possible consequences and the individual's own preferences. Yet firms and markets are supposed to be alternative means of 
coordinating human activity, so presumably they should also be different in nature and should therefore be analyzed on different bases.

In economic analysis "real people" have been replaced by abstract, mechanistic utility functions. The arguments of the utility function are typically restricted to "commodities", which means that the economic approach to organizations assumes an exclusively selfish attitude in human beings and ignores the possibility of their being interested in each other's welfare or in cooperation. It also ignores certain crucial variables such as individuals' "abilities" or their "attitudes" towards each other and towards "firms".

\section{Economics-Based Model of the Firm}

Neoclassical economic models start from the assumption that firms maximize their profit and show how that is what firms should do. The foundations of this idea are to be found in general equilibrium theory: competitive equilibria based on consumers' maximizing their utility and firms' maximizing their profits are Pareto-efficient; and any Pareto-efficient outcome can be produced by a competitive equilibrium.

Expressed in its simplest form and in modern terms, including a multi-period analysis, the argument can be found in Jensen (2000): managerial decisions should maximize the firm's value. This conclusion has gained wide acceptance, first in theory and then (purportedly, at least) in practice. On paper, this rule takes into account long-run considerations. All cash flows, no matter how far into the future, should be included and properly discounted. In practice, however, the value of a firm is often decided without taking much of this into account. Very often, actual stock market valuations are based more on quarterly earnings than is generally recognized, through the opinions of investment bank officials and financial analysts. In many of the scandals of the last decade, financial analysts continued to overvalue the shares until a few months, or even weeks, before the scandal broke, even though in some of the best-known cases, such as Enron, there were grounds for suspicion well before. The practical application of the value maximization rule is therefore more short-sighted than might be expected from models that claim to take the long run into account.

If one accepts that the socially optimum goal for a firm is to maximize its value, then the firm can be viewed as a principal-agent problem in a multiple version. The "principals" would be the shareholders, while everybody else in the firm should do whatever is necessary to maximize the firm value, of which they are the residual claimants. All agents are assumed to be selfish in the sense that they maximize their own utility function (Ghoshal, 2005; Gintis and Khurana, 2006; Khurana, 2007). The only way to ensure that they do what shareholders would like them to do, therefore, is by using an incentive system, typically involving shares or stock options.

As mentioned above, Ghoshal (2005) has argued that this presupposes an unjustifiably pessimistic view of human beings and that this pessimistic view can become a self-fulfilling prophecy, making human beings selfish and opportunistic where at the beginning they were not. A mechanical system of incentives based on measurable variables and applied automatically may very well accelerate the process and is diametrically opposed to the "humanistic" approach to management which, as we have seen, many researchers advocate. 


\section{Operational Problems of the Economic Models}

Consider a downsizing decision by a business firm. Seemingly, such a decision should increase profits, since it decreases an expense. Indeed, that is often the reason why the downsizing decision is made. In many cases, however, the overall impact of downsizing on the income statement is negative (Pfeffer, 1999; Cameron, 1991, 1993; Freeman and Cameron, 1993). Conceptually, analyzing a downsizing decision based only on its immediate effects on the income statement would be the equivalent, in mathematics, of counting only the partial derivative to calculate the change in the value of a function when one of the independent variables changes. The correct procedure would be to consider the total derivative, which in the case of a downsizing decision means including all the effects of the decision. The analysis should therefore take into account the possibility of a reduction of revenues in the future due to loss of morale in the workforce, lack of sufficiently qualified people, loss of credibility of management and many other reasons. Unlike in well-structured economics models, where all the relevant variables are known (though there may be uncertainty as to their value), one of the basic difficulties of making decisions in real life is that some of the variables that should be considered are not known beforehand. Most of these variables are essentially qualitative and some of them unforeseeable and therefore very difficult to estimate objectively in the short run; indeed, some may be impossible to estimate. Eventually, of course, the feedback loop will close and the positive and negative effects will become known; but even then the decision-makers may not immediately associate the cause (which occurred many months or even years before) with the effects (which have occurred at different points in time). So there is no guarantee that what the decision makers learn will be in any sense "right".

This analysis is not exclusive to downsizing decisions, of course. It can easily be extended to other areas. For instance, what if a firm puts heavy pressure on its suppliers to lower their prices? On the one hand, this might improve the firm's profits; on the other, it is bound to elicit negative reactions from suppliers, possibly leading to lower quality, late delivery, poor service and, in extreme cases, supplier bankruptcy. Or what if a firm treats its employees in a "dehumanized" way, i.e., not listening to their proposals, ignoring their personal needs, and so on? Again, the firm may save money in the short run, but eventually the more competent people may leave and those who stay may perform poorly. Or what about environmental damage? For the sake of short-run profit, the firm may create a hostile environment in which government places even stricter limits on companies' freedom.

In all such cases, management may make the wrong decision for the sake of immediate gains that are more than offset by subsequent losses, or because it overlooks important variables that should have been considered. Conventional economic models do not inquire into the decisionmaking process, so the problem may be considered solved by a sort of Darwinian argument whereby firms that make the right decisions survive, while those that do not make the right decisions disappear. This does not help decision-makers, however, who are the ones that matter in management. Inability to help decision makers is neutering management. Decision-makers need specific rules or criteria to make decisions operationally and the threat of extinction does not make things any better from a cognitive point of view. If anything, it puts pressure on management to use unorthodox methods that harm the firm more than anything else. In fact, many of the recent scandals (e. g., Enron, or most financial institutions involved in the disaster of the subprimes) originated in pressure for short-term results (quarterly earnings, growth objectives, or any kind of short-term, quantitative goals), which were supposed to enhance long-term performance. As Jensen (2002) argued, telling the truth to Wall Street, at the risk of 
provoking an adverse reaction, might have lowered Enron's market value to some extent, but not to the levels (practically zero) it reached a few months later when the forgeries were discovered. Therefore, although profit or value maximization may be the "best" possible guide to decision-making in theory, it may not be a good guide in the short run because it is too difficult to put into practice. As Senge (2000) has suggested, when you insist on firm value maximization as a criterion for decision-making, "...it will almost always become, by default, short-term profit maximization. (...) Given a short enough time horizon, many of (the complex) feedbacks can be ignored. This is why manipulating profits over the short term is much easier than building wealth over the long term."

\section{The Fundamental Assumptions}

As stated earlier, some of the shortcomings of the economic approach to organizations come from the assumptions on which it is based. Three of these assumptions are crucial: unbounded rationality, self-interest, and absence of learning. Two others are complementary: competitive markets and production efficiency. We will examine them in turn.

\section{Unbounded Rationality}

The assumption of unbounded rationality is indeed crucial in the above examples of decisionmaking. Given unbounded rationality, any decision-maker could immediately measure the costs and benefits of any kind of decision on downsizing, procurement, human resource management or any other subject. Even in the presence of uncertainty, an unboundedly rational decisionmaker could adequately weigh the costs and benefits of the decision and face uncertainty in a perfectly rational way, consistent with his/her attitudes towards risk. For this to be true there have to be "complete markets", i.e., markets for commodities contingent on any conceivable event. Uncertainty is therefore not incompatible with unbounded rationality: bounded rationality means inability to foresee all possible contingencies, lack of knowledge of one's own preferences, even inconsistencies in those preferences, but it does not mean lack of the perfect knowledge of the future implied by certainty. In our previous example, many of the long-run effects of a downsizing decision cannot even be foreseen, let alone quantified or have contracts established on them.

The longer the time period, the greater the impact bounded rationality has on decision-making, as the number of unforeseeable contingencies increases substantially. Technology is a good example. If we think that the future development of technology can be guessed from today's situation, past developments and current research efforts, we have only to watch a sciencefiction movie produced half a century ago to realize how in many respects we have gone well beyond what anyone could have imagined at that time, while some of the inventions in the movie are, we now know, simply impossible. ${ }^{1}$

Furthermore, our knowledge about our own future preferences decreases the further we go into the future. Bounded rationality therefore makes it as good as impossible to use the maximization of firm value, long-run profit or any other quantitative variable as an operational objective.

\footnotetext{
${ }^{1}$ See, for instance, the interesting analysis in L. M. Krauss, “The Physics of Star Trek”, Basic Books.
} 


\section{Self-interest}

Value maximization naturally has a lot to do with the hypothesis of self-interest, which is one of the bases on which much of neoclassical economic theory stands. The "narrow" version of self-interest consists of individuals having their own utility functions and attempting to maximize it with absolute disregard for other people's interests and welfare. As suggested above, while this may be a useful hypothesis for analyzing the economic system as a whole, it is not a good guide for individual behavior.

For one thing, the hypothesis of narrow self-interest is descriptively false. As Ghoshal (2005) has observed, not only do mothers care for their children, or people volunteer to go to impoverished countries or regions, and so on, but also the limitations of the self-interest model "...become manifest even in careful experiments devised by economists to test their theories under controlled conditions in which 'aberrations' such as altruism or love are strictly excluded".

It should not, then, be too surprising to find people in the world of business who are willing to sacrifice part of their own welfare for the welfare of others, thus developing what might be called "transitive" motives ${ }^{2}$, i.e., motives that take into account the needs of other people within the organization and in the marketplace. Sen (1977) made a subtle but important distinction about taking the interest of others into account. He distinguished between "sympathy" and "commitment". "Sympathy" is in fact a form of self-interest: if you see a child being tortured (to use Sen's example) and this distresses you so much that you want to stop it, then this is "sympathy". If the same fact does not affect you personally but you believe that it should not happen and are willing to commit some of your own resources to stop it, that is "commitment". Transitive motives, in the sense I use the word here, have to do mainly with commitment and, more specifically, commitment to specific people.

"Enlightened" self-interest is not much better than plain, narrow self-interest. "Enlightened selfinterest" is an expression originally used by Alexis de Tocqueville (2005, part II, Ch. VIII) ${ }^{3}$. He thought that "enlightened self interest" was common in the US, producing results that were probably mediocre from the point of view of developing virtues but could be considered necessary for the benefit of society in general. According to Tocqueville, Americans thought that narrow, egoistic attitudes were self-defeating and therefore often thought in terms of "enlightened self-interest" as a second best. He was critical of that position because he thought that the important things was to develop virtue in individuals, so that all individuals were truly "committed" to doing the right thing. In his analysis, however, as commitment can be difficult to obtain, one might opt for "enlightened self-interest" and mediocre results in preference to the results that would be obtained if everybody were narrowly selfish.

As we will see, commitment is essential in business firms if they are to serve their customers' interests. Enlightened self-interest is insufficient to develop a sense of "mission" to solve customers' needs and at the same time develop a strong sense of unity within the organization.

\footnotetext{
${ }^{2}$ See Rosanas (2008). I am indebted to Domènec Melé for suggesting the use of this adjective.

3 The original expression in French was "l'intérêt bien entendu", i.e., literally, "self-interest well understood", which is slightly different from "enlightened self-interest".
}

6 - IESE Business School-University of Navarra 


\section{Absence of learning}

The third critical element (missing, in fact) in neoclassical economic analysis is learning. To be sure, there is a branch of game theory in which some type of learning is taken into account. But it is a very narrow concept of learning, essentially to do with Bayesian updating of probabilities about uncertain variables. The kind of learning we are talking about here includes this, but goes well beyond it. It has to do with knowledge, of course, but also with abilities, on the one hand, and attitudes, wants and preferences, on the other.

Whenever an interaction between two people takes place, three kinds of results are always present (Rosanas, 2008). First, the explicit results of the interaction, which are related, of course, to what the two individuals intended. An action can be said to be effective if the results are those the individual who started the interaction expected and ineffective if they are not. The interaction also has effects on the individuals themselves, in that afterwards: (1) they know better to what extent the explicit results satisfied their expectations, and (2) how good the experience with the other person participating in the interaction was and therefore whether they want to interact with this other person again in the future. In other words, they learn. From the point of view of each of the participants in the interaction, therefore, besides the explicit results of the interaction, there are always two other kinds of results: what the individual who started the interaction learns and what the other person learns. What these two individuals learn will condition the future of their interactions and, thus, of the organization.

\section{Competitive Markets and Efficiency in Production}

Besides the above three crucial assumptions (which are complementary for some purposes, mainly that of analyzing the markets that surround organizations, and to some extent may be considered more technical, although they have considerable implications), economic approaches typically assume: (1) that the output to be obtained from the inputs is determined by a production function; and (2) that all transactions between firms and consumers go through competitive markets.

If the production function entirely determines the output from a given mix of inputs, then production is "efficient" (i.e., it is impossible to produce more output from the same inputs, or the same output with fewer inputs). This is what Leibenstein (2002) calls X-efficiency, to distinguish it from other concepts of efficiency (e.g., Pareto efficiency, in the sense used above). Needless to say, this hypothesis is at odds with learning because, in practice, learning means expanding the efficient frontier. The hypothesis also excludes bounded rationality, because efficiency means that the firm knows all the possibilities and is able to choose the right one. Self-interest, then, leads to profit (or value) maximization.

Markets are perfectly competitive when a single producer can sell as much of the product as it produces, and a single consumer or firm can buy as much of it as it wants, without affecting the price in either case. Again, this is incompatible with learning, because if you accept the competitive hypothesis, all firms are at the efficient frontier.

Suppose the two hypotheses hold, i.e.:

(a) the firm can find a supply of the kind of labor it needs at a known price in a competitive market and the same applies to raw materials and intermediate products, 
financial inputs, and so on. Also, the firm can sell as much as it wishes of an undifferentiated product at prevailing market prices.

(b) production is X-efficient, i.e., the production function completely determines the output given the inputs.

If these two hypotheses hold, together with unbounded rationality, then the classical argument of profit maximization (or value maximization, in more modern terms) is unassailable. A "dollar taken out of the economy", to use Jensen's (2000) expression, is perfectly well defined and the amount of product to be obtained is known as well, so that the comparison between the value of the product and the value of the input can be readily made.

These hypotheses do not hold in practice, however. One crucial factor is labor. With the possible exception of unskilled workers, by definition there cannot be a competitive market for labor. In today's economy, where an employee's specific knowledge is crucial and part of that knowledge is implicit, embedded and useful only to a specific firm, it is impossible to find that kind of knowledge readily available in the market (Polanyi, 1958; Nonaka, 1994; Andreu 2009). Therefore, the meaning of "a dollar taken out of the economy" is ill-defined. And of course, the more differentiated the product and the more specific the knowledge required, the more illdefined that dollar becomes.

To the extent, therefore, that the firm has a differentiated product and needs specific raw materials or supplies the same is bound to be true of most suppliers. The same can be argued, of course, for all other stakeholders.

The efficiency assumption is quite a strong one, too. From the point of view of the whole economy, again the Darwinian hypothesis is right. Given equal technology, a firm that is not $\mathrm{X}$-efficient will disappear because efficient competitors (which always abound in competitive situations) will take the whole market. This does not solve the problem of a specific firm, however. For a specific firm, achieving efficiency is one of the basic goals. X-efficiency is therefore endogenous, one of the variables that will determine a firm's success or failure.

Hence, if "a dollar taken out of the economy" is likely not to be well defined, the amount of product obtained may not be well defined either, and what can be obtained in an imperfect market for a unit of product still less. Therefore, the value maximization rule may not be applicable. What in fact happens is that in every interaction between "the firm" and another party a relationship is created that may be either satisfactory for both, unsatisfactory for one and satisfactory for the other, or unsatisfactory for both. In practice, "the firm" means any person who belongs to the firm; and "another party" means any person that represents that other party.

\section{An Alternative Framework for Analysis of Managerial Action: Basic Assumptions}

An alternative formulation must depart from some of the assumptions on which the economics model is based. It would include: (i) bounded rationality; (ii) "satisficing" behavior; (iii) qualitative, unmeasurable organizational goals: limitations of formal evaluation and control systems; (iv) long-run and institutional identity; (v) wider individual objectives and motives; (vi) competitive advantage through knowledge; and (vii) organizations as communities: loyalties and identification. We will discuss these in turn. 


\section{Bounded rationality}

Individuals are boundedly rational. They cannot choose the optimal course of action because they do not know all the possible courses of action. They cannot do the computations and inferences to analyze the actions they know thoroughly and they are not certain as to what level of satisfaction they will achieve through the results of their actions. This is one aspect of bounded rationality which, though stated in Simon's original formulation of the concept ("It is a commonplace experience that an anticipated pleasure may be a very different sort of thing from a realized pleasure" - 1997, p. 95), is often overlooked nowadays, perhaps on the assumption that it is already included in value maximization. If we analyze the firm in more depth, however, we will see how it is crucial to think of bounded rationality both with respect to consumers and with respect to employees: we contend that management (or, more abstractly, "firms") should attempt to satisfy the real needs of both groups, so as to leave them genuinely satisfied after the event, not merely in terms of what they thought attractive or desirable before the event.

The first aspect of bounded rationality mentioned above is often overlooked as well, i.e. the fact that action alternatives are not freely available for the decision-maker to pick the one she prefers. Instead, they have to be generated at a cost. The cost would include at least the opportunity cost of the decision-maker's time; more often, however, other explicit costs have to be included as well. In fact, whether it is worth spending time and money on looking for alternatives is part of the problem. As a result, often it is not a matter of choosing among different, already available alternatives, but of accepting one that has been found to sufficiently meet all the criteria the organization considers relevant.

Finally, of course, bounded rationality implies the inability to precisely calculate the results of any alternative. This is the criterion most often used in recent times and was used at the beginnig of this paper in the context of a downsizing decision.

\section{"Satisficing" behavior}

Simon's concept of "satisficing behavior" is the ideal complement of bounded rationality, and it is a crucial concept when several criteria have to be met. It is impossible to maximize two (or more) variables at the same time, unless the variables to be maximized are all monotonic transformations of each other (Jensen, 2001); and having a multiplicity of variables often leads to poor decision-making, resulting in a "performance freeze" (Ethiraj and Levinthal, 2009).

Thus, when we say that several criteria have to be met, either we are saying that we are aiming for a satisficing level of all the variables and will not even attempt to maximize anything; or else we must maximize only one variable, which has priority over all the others, which act as constraints. In a classical paper, Simon (1964) expressed this idea very clearly:

"In decision-making situations of real life, a course of action, to be acceptable, must satisfy a whole set of requirements, or constraints. Sometimes one of these requirements is singled out and referred to as the goal of the action. But the choice of one of the constraints, from many, is to a large extent arbitrary. For many purposes it is more meaningful to refer to the whole set of requirements as the (complex) goal of the action. This conclusion applies both to individual and organizational decision-making."

This analysis has important implications. A certain minimum of each variable must be obtained in order to have a satisfactory solution. Below that minimum for each variable there are no 
trade-offs one can think of, so conventional analysis based on continuous utility functions and differential calculus is not applicable. If one solution does not satisfy the minimum satisficing levels for all variables, the decision-maker has no alternative but to keep generating better alternatives. Under bounded rationality, one would expect this to occur quite frequently. In fact, success in business may have more to do with finding good alternatives than with choosing between readily available alternatives.

Occasionally, there may be more than one of the generated alternatives that meets all the criteria. In this case, one could choose "freely" (at random) from these alternatives, although it would seem logical to choose on the basis of maximizing one of the criteria.

\section{Qualitative, Unmeasurable Organizational Goals: Limitations of Formal Evaluation and Control Systems}

It follows from the analysis above that: (1) many of the important variables in organizations are impossible to measure with any degree of accuracy; and (2) there are several dimensions to the goals of any company. Under these conditions, it is impossible for formal evaluation and reward systems to push people in the right direction (Holmstrom and Milgrom, 1991; Baker, 1992; Gibbons, 1998). The basic idea in these analyses is that if there is an underlying variable (profit, firm's value, or any other) that the firm should maximize, this variable is only imperfectly measurable, so any explicit variables being measured will be only imperfectly correlated with the underlying variable.

The phenomena analyzed in the previously cited papers of Baker (1992) and Gibbons (1998) largely explain the recent scandals. Specifically, suppose that the underlying variable the firm wants to increase (say, long-run firm value) is not perfectly measurable today and that the performance variable measured is only imperfectly correlated with that underlying variable. Then, when considering two specific courses of action, $a_{1}$ and $a_{2}$, it may well be that $a_{1}$ is better than $a_{2}$ from the point of view of the performance measure but is worse from the point of view of the underlying value. Suppose now that the firm has an incentive system that rewards measured performance, e.g., a linear compensation system where employees are paid a fixed amount independent of performance, plus an amount for each unit of measured performance. For the firm as a whole $a_{2}$ is better than $a_{1}$, but the opposite is true for the decision-maker. Hence, the decision-maker is quite likely to choose $a_{1}$. In the extreme case, an agent could earn higher incentive pay by manipulating performance measurements, lying or cheating.

Therefore, a system that was supposed to perfectly align the interests of the professional managers with the long-run interests of the stockholders has in fact achieved the opposite. ${ }^{4}$

\section{Long-Run and Institutional Identity}

There is another sense in which short-run maximization of any variable may not be desirable. Often, when we speak of the long run, we do not refer so much to the time horizon itself as to other variables related to the institution's values. Selznick made this point already in 1956:

\footnotetext{
${ }^{4}$ For a pathetic example of this, see in youtube what Richard Fuld, former CEO of Lehman Brothers, had to say in the Congressional Hearings about the crisis.

http://www.youtube.com/watch?v=--cifEkRXc4\&feature=related
}

10 - IESE Business School-University of Navarra 
"To take advantage of opportunities is to show that one is alive, but institutions no less than persons must look to the long-run effects of present advantage. In speaking of the 'long run' we have in mind not time as such but how change affects personal or institutional identity. Such effects are not usually immediately apparent, and therefore we emphasize the lapse of time. But changes in character or identity may occur quite rapidly.

Leadership is irresponsible when it fails to set goals and therefore lets the institution drift. The absence of controlling aims forces decisions to be made in response to immediate pressures." (Selznick, 1956, p. 143)

This last paragraph is particularly important. The only way for an organization to avoid the long-run consequences that would make it drift is to have "controlling aims". Those "controlling aims" have to be well-established decision-making criteria aimed at ensuring that the organization preserves its identity. This, in turn, implies a multiple-criteria decision-making process. Profit, value or some such financial variable is surely one criterion; but we will need more criteria if we want to preserve the organization's personality. This is much more difficult to put into practice than a single-criterion decision-making process, but it is indispensable. Later I will attempt to show how this can be done.

\section{Wider Individual Objectives}

There is something else missing from the conventional economic approaches to organization. All people (including shareholders) actually have wider objectives: besides wealth or economic value they also want something else. This something else should include the interests of other people affected by the firm or its actions: first and foremost, the firm's employees, suppliers and customers. The concern for other affected people or institutions is what gave birth to the socalled "stakeholder theory of the firm" (Freeman, 1994). Jensen (2000) objects that when there is no single maximand, the firm does not know what to do; but he recognizes that narrow firm value maximization may lead to mistakes in the short run. Therefore, he advocates an "enlightened stakeholder theory" and argues that it is practically equivalent to "enlightened value maximization": respecting the interests of all stakeholders, but adding "the simple specification that the objective function of the firm is to maximize total long-term firm market value". This is of course well-intentioned, but it is difficult to ascertain whether it can be true because, unlike shareholder theory, stakeholder theory is not a clear and well-defined theory connected with a more general theory of resource allocation. All the same, it represents a substantial departure from the doctrine of narrow self-interest that has been so popular in recent years, both in theory and in practice.

\section{Motives of Individuals}

A person's motives clearly exceed the economic variables that affect only the person herself. That there are other motives besides compensation and monetary incentives ("extrinsic motives") has been recognized in the behavioral literature for quite a while (e.g., Maslow, 1954; McGregor, 1960; Porter and Lawler, 1968). "Intrinsic" motives, i.e., motives related to the job itself, the satisfaction of working with other people, doing something for others, and so on, have also been recognized in the economics literature in the last few years (e.g., Kreps, 1997). Osterloh and Frey (2003) state: 
"Extensive research accumulated over recent decades has established the importance of a very different kind of motivation in the firm, namely intrinsic motivation. In this case, an activity is valued for its own sake and is self-sustained. The work content itself provides satisfaction or utility.

Intrinsic motivation is indispensable when external incentives cannot solve the problems of social dilemmas, either because behavior is not observable, or because the outcomes are not attributable to individuals. If there is an intrinsic motivation to work and to cooperate, contributing to the common good ceases to become a social dilemma."

Intrinsic motivation, thus defined, is indispensable in situations where there are severe limitations in the measures of the output and results of the firm, as it was suggested in the previous section. Often, however, "intrinsic motivation" is a composite of different factors. In Osterloh and Frey, for instance, intrinsic motives include what, following Frey (1997), they call "obligation-based" or "pro-social motives", which are clearly different from enjoying an activity for its own sake, irrespective of other people involved.

Here I prefer to reserve the expression "intrinsic motivation" to denote the pleasure (or displeasure, if it requires effort) of simply doing a good job, while I have already used the expression "transitive" motivation to refer to motives targeted at other people's well-being. Transitive motives have to do with an individual's wish to satisfy someone else's needs, which is crucial when it comes to defining the mission of an organization. They are different from "pro-social" or "altruistic" motives in that "pro-social" or "altruistic" motives are to some extent abstract, aimed at society as a whole, perhaps more related to "sympathy", whereas transitive motives have to do with specific people (customers, employees, other stakeholders), whose needs one may attempt to satisfy, and thus related to "commitment".

\section{Competitive Advantage Based on Knowledge and Distinctive Competence}

The competitive advantage of a firm rests heavily upon a type of knowledge that is produced internally, is somewhat implicit (as opposed to explicit) and can be used only within the firm itself, it being impossible to sell it as a market good (Nonaka, 1994; Andreu, 2009). Already in 1945 Hayek expressed the idea that "practically every individual has some advantage over all others because he possesses unique information of which beneficial use can be made only if the decisions depending on it are left to him or are made with his active cooperation". Today, this is truer than ever: knowledge has become crucial in all sectors of economic activity.

This has an extremely important implication. If it is impossible to have a perfect evaluation and incentive system (except perhaps in marginal, mechanical, trivial jobs), then we cannot rely on extrinsic motives to make individuals do what is good for the organization. For individuals to cooperate effectively in an organizational context, therefore, they must have intrinsic or transitive motives.

\section{Organizations as Communities: Loyalties and Identification}

A "good climate", "good team work" or, more succinctly, "union" between members of an organization has always been considered crucial for an organization to function. The individualism implicit in most economic theories seems to have obliterated this crucial fact lately. Pfeffer (2005) argues strongly in favor of the idea of organizations as communities: 


\begin{abstract}
"Organizations that are more communal have arrangements for helping employees in need, offer more generous employee benefits and assistance, eschew anti-nepotism policies, have more company-sponsored social events, are better at resolving work-family issues, and foster long-term employment relations. (...) The logic linking the less communal aspect of companies and the rise of distrust, disengagement, and diminished satisfaction, although not extensively empirically demonstrated, seems clear. Trust is enhanced through longer-term interactions and by believing that the other party is taking your interests into account."
\end{abstract}

Individuals' identification with or loyalty to organizational objectives, which classical writers like Barnard (1938) or Simon (1957) considered to be the basis of organizational efforts, has lost ground to the individualism implicit in today's economics-based analyses. In Barnard's words (1938, chapter 7):

"... to me, at least, it appears utterly contrary to the nature of man to be sufficiently induced by material or monetary considerations to contribute enough effort to a cooperative system to enable it to be productively efficient to the degree necessary for persistence over an extended period. If these things are true, then even in purely economic enterprises efficiency in the offering of non-economic inducements may be as vital as productive efficiency."

Simon (1957, Chapter VI) expresses a complementary point of view:

"Individuals are willing to accept organization membership when their activity in the organization contributes, directly or indirectly, to their own personal goals. The contribution is direct if the goals set for the organization have direct personal value for the individual - church membership is a typical example of this. The contribution is indirect if the organization offers personal rewards - monetary or other - to the individual in return for his willingness to contribute his activity to the organization. Employment in a business concern is a typical example of this. (...) The phrase "personal goals' which is used here should be understood in a broad sense. It is by no means restricted to egoistic goals, much less to economic goals. 'World peace' or 'aid to the starving Chinese' may be just as much a personal goal for a particular individual as another dollar in his pay envelope. The fact that economic incentives frequently predominate in business and governmental organizations should not obscure the importance of other types of inducements."

Both Barnard and Simon, thus, attach a great weight to non-monetary motives and think that firms should take care of the motives of the individuals (the famous concept of "efficiency" in Barnard), so that individuals can identify with the firm.

\title{
An Alternative View of Organizations ${ }^{5}$
}

This set of assumptions has strong implications for how we view organizations. For one thing, maximizing value cannot be the firm's goal: maximization is not possible because of the hypotheses of bounded rationality and satisficing behavior; and value maximization might not even be desirable if it is done at the expense of long-run qualitative variables. In fact, the basic

\footnotetext{
${ }^{5}$ In this section, I will draw freely on the work of Pérez López (1993).
} 
goal of the firm has to be to adequately and simultaneously satisfy the needs of all stakeholders.

In fact, if any one group of people is to be singled out as the main beneficiaries of the organizational goal it is customers. This was already seen by Simon (1957, Ch. VI). Specifically and operationally, customers define the basic purpose of organizational action: the goal is precisely to deliver a product or service that solves their needs.

\section{Mission}

This basic purpose is what is sometimes called the "mission" of the firm. It may have been Selznick (1957) who first used this (originally military) term in a management context. In Selznick's original formulation, the mission is a guide to what has to be done, the general purpose that gives meaning to all particular actions that have to be undertaken, and it is in this sense that we use the word here. It is very unfortunate that nowadays the "mission" of a firm is often equated with a set of high-sounding phrases void of content. Most "mission statements" in published annual reports are meaningless, fine words saying how much the firm wants to be the best in everything it does and how much it cares about shareholders, customers, the environment and everybody else in the world, usually without explaining how it sets priorities, how or to what extent it guides employees' actions, or to what extent it sacrifices short-run success for long-run advantage. ${ }^{6}$

Here, "mission" means what kind of customer needs the firm will try to satisfy. For instance, the firm may say that its mission is to help to keep the inhabitants of a particular geographical area warm in winter. It can do that with electricity, fuel oil, coal, insulation or other means, possibly including some that have not been invented yet. But what the firm wants to do and considers to be its mission is to solve the heating needs of a specified population group.

In order to be interested in the organizational goal as just defined, the organization's employees need to have what we have called transitive motives, i.e., they have to want to solve the customers' problem (i.e. keep them warm). If the employees have only extrinsic motives, they will just want to do whatever they get rewarded for doing. What's more, there cannot be an "objective" reward for satisfying customer needs because such satisfaction is subjective by its very nature; not to mention the fact that whether customers are really satisfied or not may not be known until years after the sale is completed. If employees have only intrinsic motives, they may produce a product that is technically perfect and that they enjoy producing, but that is unfit or impractical for customers. In either case, consumers are obviously not going to be satisfied, there will be no repeat business, and stockholders will be unsatisfied as well.

It is interesting at this point to recall Hayek's argument that employees' active cooperation is needed to make full use of the personal, relevant information they have (Hayek, 1945). If the firm does not obtain such active cooperation, decisions are likely to be mediocre and the firm will not be competitive. If a firm wants to limit itself to producing a product that is as good as possible from a technical point of view, then it may be solving the wrong problem for the

\footnotetext{
${ }^{6}$ Just to illustrate, I have copied this completely meaningless "mission statement" from the annual report of an international firm in the paper industry:

"Our mission is to grow in the production and distribution of paper, with a commitment to quality and service that satisfies the needs of the customer, all this from criteria of economic profitability, social responsibility, and sustainability."
} 
customer. In contrast, if the firm actually tries to solve the consumer's problem, it may have a competitive advantage and be highly profitable. In order to do that, however, the firm needs to develop transitive motives in its employees. Unless its employees have transitive motives, they are not going to be interested in solving customers' problems. Trying to obtain as much money as possible for stockholders may just be putting the cart before the horse.

\section{Distinctive Competence}

To fulfill its mission and develop a competitive advantage, a firm needs to have a "distinctive competence" that defines its character and identity. Distinctive competence is the opposite of opportunism (seizing every opportunity to make an immediate gain) because it is developed in precisely the opposite way, i.e., by specializing in satisfying a particular kind of need and developing the products to do so most effectively. Distinctive competence is created on the basis of an organizational mission. Identifying individuals with the targeted need is what creates the organization's ability to meet that need and may give the organization an advantage over competitors that have neither the sense of mission nor the knowledge to do so.

Knowledge is a crucial resource, especially in today's "knowledge economy". Part of this knowledge, as we said, is: (1) specific to the individual firm in the context of its strategy and mission; and (2) implicit, in that people may not be aware that they know what they know (Polanyi, 1958). Developing a distinctive competence has to do with these kinds of knowledge. Knowledge that is standard and explicit can be acquired in the market, either in the form of literature and technology or in the form of a person who possesses the knowledge. Precisely for that reason, however, distinctive competence cannot be based on such knowledge. Instead, it has to be based on knowledge that is specific not only to a particular job, but also to the person and the firm. Firms in the same industry but with a different sense of mission and a different strategy will develop specific knowledge that has very little in common.

The core issue here is how a sense of mission and identification can lead to the development of implicit, specific knowledge. If specific knowledge is tied to a particular firm's mission and strategy, it is by definition useful only to that firm, not to any other. Extrinsic motives can therefore never be sufficient to induce people to invest in this type of knowledge. Why would anyone develop it if they do not identify with their particular firm and its mission? It is the kind of knowledge that has no market value and adds no market value to the person acquiring it, since by definition it can be used only in the firm in which it originated. To invest in it, therefore, a person must expect to stay in the firm, which is unlikely to happen unless the individual identifies with the firm; otherwise, she will be looking for another job somewhere else.

The two concepts are therefore interrelated: a firm cannot develop a distinctive competence unless its employees identify with it; and employees cannot identify with a firm unless the firm is doing something different, i.e., has a personality, a character, a distinctive competence.

The impact of any decision on an organization's distinctive competence is therefore crucial for the organization's future, but mainly in a negative sense. In other words, if a given action alternative simply takes advantage of an opportunity, the chances are that it will contribute to destroying the firm's distinctive competence and, with it, the employees' identification with the firm. Selznick saw most of these points many years ago, but we seem to have forgotten many of them recently in favor of quantitative goals: 
"In studying character we are interested in the distinctive competence or inadequacy that an organization has acquired. In doing so, we look beyond the formal aspects to examine the commitments that have been accepted in the course of adaptation to internal and external pressures. (...) we come back to the problem of maintaining institutional integrity. The ultimate cost of opportunistic adaptation goes beyond capitulation on specific issues. A more serious result is that outside elements may enter the organization and dominate parts of it. When this happens the organization is no longer truly independent, no longer making specific compromises as necessity dictates while retaining its unity and distinctive identity. Rather, it has given over a piece of itself to alien forces, making it possible for them to exercise broader influence on policy. The transformation of compromise or even defeat into partial organizational surrender can sometimes be a conscious measure of last resort, but it also occurs without full awareness on the part of the participants. In our study of the Tennessee Valley Authority, referred to above, just such a phenomenon was observed. A political compromise with local and national agricultural interests was implemented by permitting part of the TVA as an organization to be controlled by those forces, with extensive and unanticipated effects on the role and character of the agency. The avoidance of opportunism is not the avoidance of all compromise; it is the avoidance of compromise that undermines institutional integrity. Opportunism also displays itself in a narrow self-centeredness, in an effort to exploit other groups for immediate, short-run advantages. If a firm offers a product or service to other firms, expectations of dependability are created, especially in the matter of continuing supply. If supplies are abruptly discontinued, activities that depended upon them will suffer. Hence a firm's reputation for dependability and concern for others becomes a matter of great importance wherever continuing relationships are envisioned. To act as if only a set of impersonal transactions were involved, with no responsibility beyond the strict terms of a contract, creates anxiety in the buyer, threatens to damage his reputation for dependability, and in the end weakens both parties." (1957)

Distinctive competence is related to intrinsic motives on the part of individuals, i.e., the desire to do a good job, practice one's abilities, enjoy a job well done, and so on. In the previous section, we saw that identification with the organizational mission has to do with transitive motives. Thus, intrinsic and transitive motives play a key role in the development of an organization.

\section{"Internal" Mission and Identification with Organizational Goals}

As stated, we need employees to identify with the organizational goal (defined in terms of consumers' needs). But we need them to identify with one another as well. In a world in which there is very little a person can do on her own, team spirit is essential in any organization, no matter how small. In other words, we need organizational "unity", where all employees identify with the organizational mission and, at the same time, with each other, and where each cooperates with the rest of the organization in doing whatever has to be done in order to achieve the goal. This is what Pérez López (1993) calls the "internal mission", i.e., the ("external") mission as internalized by individual employees. Unity thus becomes crucial to firms' long-run survival and competitive advantage.

Transitive motives come into the picture here again. Unity will only be achieved if employees have transitive motives towards each other; otherwise, they can be expected to behave bureaucratically or even do a technically perfect job, but without actively cooperating with the rest of the people in the organization in solving the customer's real problem. Employee 
development is possibly the most important means of building unity, competitive advantage and profitability at the same time; and it has to be done in all three dimensions of extrinsic, intrinsic and transitive motives.

Every individual has extrinsic motives, because every individual has physical needs that must be satisfied (food, shelter, etc.). Also, every individual has intrinsic motives (the need to learn and do a good job). Transitive motives are to some extent spontaneous, but also need to be developed. This is one of the key tasks of management: to help individuals develop the intrinsic and transitive motives they need in order to achieve organizational goals. It is not an easy task, though, and cannot be done directly. It is easy to create or develop extrinsic motives through an incentive system, to the extent of displacing or even destroying intrinsic and transitive motives (Frey and Jegen, 2001), but it is impossible to create and develop intrinsic and transitive motives in the same way. Possibly, the only way to do it is by creating a culture in which everybody in the organization promotes, respects and praises transitive motives. Transitive motives may help develop intrinsic motives, but in contrast, developing extrinsic motives may kill both intrinsic and transitive motives.

To sum up, organizations can be viewed as having a mission, which has to do with satisfying their customers' real needs, as opposed to short-run perceived needs or wishes. In order to induce employees to cooperate in doing this, firms need employees to have both intrinsic and transitive motives. Transitive motives will make employees try hard to solve customers' problems, while intrinsic motives will help solve the problem in a technically correct way. For employees to cooperate with each other and invest in specific knowledge, which is the key to distinctive competence and therefore to competitive advantage, it is crucial that they integrate and identify with the firm. This will naturally result in greater profitability: if a firm solves its customers' real needs, customers will purchase its products and the firm will survive indefinitely. Profitability is therefore an outcome of the firm's actions, not the starting point; the scorecard rather than the compass. ${ }^{7}$

\section{Implications for Managerial Decision-Making}

Under the assumption of competitive markets for the company's products, as well as raw materials, labor and all other inputs, managerial decisions have only an economic component and can be made almost mechanically. The criterion on which they have to be based is, of course, the maximization of firm value.

We have shown that this is generally unrealistic, although for some simple decisions it may not be too unrealistic. A decision of the kind taught in elementary cost accounting courses (e.g., about adding or dropping a product that is similar to many others the firm already has, or about accepting a special order at a special price, and so on) can be made ("ceteris paribus", one might add) on the basis of contribution and profitability alone, which amounts to maximizing the firm's value. If the decision affects more than one period, present value analysis leads to maximization of the firm's profit and value.

\footnotetext{
${ }^{7}$ A word of caution is in order here with respect to profitability, though. One might argue that a firm can have an excellent product, but that the product cannot be produced profitably because consumers cannot pay the cost. If that is the case, the firm is not solving consumers' real needs, as that requires making a product consumers can afford.
} 
With more complex decisions of the kind suggested above (downsizing, etc.), however, a single criterion of profit or value maximization is unrealistic and incomplete. Of course, there has to be a quantitative analysis of the financial variables and the result of this analysis will be one of the (important) inputs to the decision process. Firms need to survive, so they must make some profit (all costs taken into account) over an extended period.

More generally, besides the financial variables there may be other quantitative variables where the firm either has to obtain a certain minimum or it will not survive, or variables that are indices of other important variables. Examples for certain decisions might include on-time delivery, absenteeism, statistical distribution of demand for different products and so on. All of them have to do with achieving specific, pre-established, quantitative goals. The degree to which these goals are achieved is usually expressed in terms of effectiveness. Effectiveness is important, of course, but it follows from the previous analysis that it is not nearly enough. We need two more criteria.

\section{Application: Three Criteria for Decision-Making}

Effectiveness is surely the first obvious criterion for decision-making and may have many subcriteria, consisting of different quantitative variables, including the financial ones.

As a second criterion, we have to evaluate the firm's distinctive competence or, rather, the extent to which distinctive competence is affected by the firm's decisions. This means answering the following type of question: Is the action alternative we are contemplating going to teach the company something that is congruent with the direction set by the company's mission? Will it help to make the company progress in that direction? Or is it an alternative that does not contribute to the development of distinctive competence but simply provides some high financial contribution and so merely increases effectiveness? If that is the case, it is what Selznick called "opportunistic adaptation", which he considered a serious threat to distinctive competence (Selznick, 1957).

Assessing the impact on distinctive competence is crucial, but by its very nature qualitative. The decision maker has no alternative but to make a subjective assessment. Any attempt to quantify certain dimensions of distinctive competence will not exhaust the concept. In other words, if the decision-maker attempts to use quantitative indices to assess the impact, there will always be a residual that is omitted, possibly a very important residual that cannot be measured. Indices may be useful for assessing distinctive competence, but once they have been quantified they become part of effectiveness, the first criterion evaluated. If one believes that "there is more to it" than the value of the index, i.e., that there is a qualitative component that is important and cannot be measured, then this assessment is not only necessary but at least as important as a quantitative measurement of effectiveness.

Finally, we have to consider the effects of the proposed courses of action on unity. The type of question to be asked now is: to what extent does this decision encourage employees to identify with one another and with the organization's mission? Here, too, there is a minimum ("satisficing") level that must be met.

There may be trade-offs between the three variables, but they are extremely difficult to handle, partly because a ("satisficing") minimum of the three variables is needed, so no amount of effectiveness will compensate for a destruction of unity or opportunistic adaptation. Bounded rationality, on the other hand, means that only a few action alternatives will be explicitly 
considered. Therefore, when an alternative is found that does not satisfy the three minimum levels of aspiration, new alternatives must be generated until one is found that does.

No attempt should be made to maximize anything (typically, there will be no opportunity to do so), but if in some cases one has to choose between two alternatives that meet the minimum levels of the three variables, the one that has the most favorable impact on unity should be chosen, because unity is the "engine" at the beginning; distinctive competence and effectiveness are merely the consequences. An organization whose priority is to protect its unity and distinctive competence will inevitably have good results from the point of view of effectiveness. 


\section{References}

Andreu R. (2009), "Knowledge, Learning and Competitive Advantage: Implications for the Management Profession", 1st IESE Conference on "Humanizing The Firm And The Management Profession”, IESE Business School.

Baker, G. (1992), Incentive Contracts and Performance Measurement, Journal of Political Economy, 100(3): pp. 598-614.

Barnard, Ch. (1938), “The Functions of the Executive”, Boston, Harvard University Press.

Cameron, K. S. (1991), Downsizing can be hazardous to your future, H. R. Magazine, May.

Cameron, K. S. (1993). Organizational downsizing, in George Huber and William Glick (Eds.), Organizational Change and Redesign, New York: Oxford University Press, pp. 19-65.

Cameron, K. S., Dutton, J. E. and Quin, R. E. (eds.) (2003), "Positive Organizational Scholarship”, San Francisco: Berret-Koshler.

Davis, J. H., Schoorman, F. D. and Donaldson, L. (1997), Toward a stewardship theory of management, Academy of Management Review, 22: pp. 20-47.

Donaldson, L. (2002), Damned by Our Own Theories: Contradictions Between Theories and Management Education, Academy of Management Learning \& Education, 1: pp. 96-106.

Donaldson, L. (2005), For Positive Management Theories While Retaining Science: Reply to Ghoshal, Academy of Management Learning \& Education, 4: pp. 109-113.

Ethiraj, S. and Levinthal, D. (2009), Hoping for A to Z While Rewarding Only A: Complex Organizations and Multiple Goals, Organization Science, 20(1): pp. 4-21.

Ferraro, F., Pfeffer, J. and Sutton, R. (2005), Economics Language and Assumptions: How Theories May Become Self-Fulfilling, Academy of Management Review, 30(1): pp. 8-24.

Freeman, R. E. (1984), “Strategic management: A stakeholder approach”, Boston: Pitman.

Freeman S. J. and Cameron, K. S. (1993), Organizational downsizing: A convergence and reorientation framework, Organizational Science, 4: pp. 10-29.

Frey, B. (1993), Does monitoring increase work effort? The rivalry with trust and loyalty, Economic Inquiry, XXXI: pp. 663-670.

Frey, B. S. (1997), "Not Just for the Money: An Economic Theory of Personal Motivation", Brookfield: Edward Elgar.

Frey, B. S. and Jegen, R. (2001), Motivation Crowding Theory: A Survey of Empirical Evidence, Journal of Economic Surveys, 15(5): pp. 589-611.

Friedman, M. (1953), The Methodology of Positive Economics, In Friedman, M., Essays in Positive Economics, Chicago: University of Chicago Press.

Ghoshal, S. (2005), Bad Management Theories are Destroying Good Management Practices, Academy of Management Learning \& Education, 4: pp. 75-91. 
Gibbons, R. (1998), Incentives in Organizations, Journal of Economic Perspectives, 12(4): pp. 115-132.

Gintis, H. and Khurana, R. (2006), Corporate Honesty and Business Education: A Behavioral Model. In Paul J. Zak (ed.), Moral Markets: The Critical Role of Values in the Economy, Free Enterprise: Values in Action Conference Series, Princeton University Press, 2007.

Hamel, G. (2007).

http://discussionleader.hbsp.com/hamel/2007/10/is_it_really_possible_to_reinv.htlm

Hayek, F. A. (1945), The Use of Knowledge in Society, American Economic Review, 35(4): pp. 519-530.

Jensen, M. (2000), Value Maximization, Stakeholder Theory and the Corporate Objective Function, in M. Beer and N. Nohria (eds.), Breaking the Code of Change, Boston: Harvard Business School Press, Also in Journal of Corporate Finance, Fall 2001.

Jensen, M. (2002), “Just Say “No" to Wall Street”, NOM Working Paper No. 02-01, Harvard Business School.

Khurana, R. (2007), "From Higher Aims to Hired Hands", Princeton and Oxford: Princeton University Press.

Kreps, D. (1997), Intrinsic Motivation and Extrinsic Incentives, American Economic Review, 87(2): pp. 359-364.

Leibenstein, H. (2002), “Beyond Economic Man”, Second Edition, Cambridge, Mass.: Harvard University Press.

Maslow, A. (1954), “Motivation and Personality”, New York: Harper and Row, Publishers, Inc.

McGregor, D. (1960), “The Human Side of the Enterprise”, New York: McGraw-Hill Book Company.

Munier, B., Selten, R. et al. (2003), Bounded Rationality Modeling, Marketing Letters, 43: pp. 197-200.

Nonaka, I. (1994), A Dynamic Theory of Organizational Knowledge Creation, Organization Science, 5(1), February.

Osterloh, M. and Frey, B. (2003), "Corporate Governance for Crooks? The Case for Corporate Virtue”, Working paper ISSN 1424-0459, Institute for Empirical Research in Economics, University of Zurich.

Pearce, J. L. (2003), What Do We Know and How Do We Really Know It, Academy of Management Review, 29(2): pp. 175-179.

Pérez López, J. A. (1993), “Fundamentos de la Dirección de Empresas”, Madrid: Ediciones Rialp.

Pfeffer, J. (1999), “Labor Market Flexibility. Do Companies Really Know Best?”, Research Paper 1592, Stanford University.

Pfeffer, J. (2005), "Working Alone: What Ever Happened to the Idea of Organizations as Communities?, Research Paper No. 1906, Stanford University. 
Polanyi, M. (1958), “Personal Knowledge”, Chicago: The University of Chicago Press.

Porter, L. W. and Lawler, E. E. (1968), “Managerial Attitudes and Performance”, Homewood, Ill: Richard D. Irwin, Inc.

Rosanas, J. (2008), Beyond Economic Criteria: A Humanistic Approach to Organizational Survival, Journal of Business Ethics, DOI 10.1007/s10551-006-9341-9.

Selznick, P. (1957), "Leadership in Administration", Berkeley, Los Angeles and London, University of California Press.

Sen, A. (1977), Rational Fools: A Critique of the Behavioral Foundations of Economic Theory, Philosophy and Public Affairs, 6: pp. 317-44.

Senge, P. (2000), The Puzzles and Paradoxes of How Living Companies Create Wealth, in M. Beer and N. Nohria (eds.), Breaking the Code of Change, Boston, Mass.: Harvard Business School Press, pp. 59-81.

Simon, H. (1957), “Administrative Behavior”, Second Edition, New York and London: The Free Press.

Simon, H. (1964), On the concept of organizational goal, Administrative Science Quarterly, 9: pp. 1-22.

Tocqueville, A. (1981) (originally, 1840), "De la Démocratie en Amérique”, Paris: Garnier Flammarion. 